\title{
Exosomal MicroRNA Expression Profiling in Patients with Lung Adenocarcinoma-associated Malignant Pleural Effusion
}

\author{
HIROYUKI TAMIYA, AKIHISA MITANI, AKIRA SAITO, TARO ISHIMORI, MINAKO SAITO, \\ HIDEAKI ISAGO, TAISUKE JO, YASUHIRO YAMAUCHI, GOH TANAKA and TAKAHIDE NAGASE \\ The Department of Respiratory Medicine, The University of Tokyo Hospital, Tokyo, Japan
}

\begin{abstract}
Background/Aim: Cytological analysis for diagnosing malignant pleural effusion associated with lung adenocarcinoma (Ad-MPE) shows limited sensitivity and novel diagnostic biomarkers are needed. The aim of this study was to evaluate the profile of four microRNAs (miRNAs) in exosomes in Ad-MPE and benign (non-neoplastic) pleural effusion (BPE). Materials and Methods: A total of 56 pleural effusion samples from patients with lung adenocarcinoma and benign diseases were collected. Exosomal miRNA expressions were evaluated using real-time quantitative reverse transcription polymerase chain reaction (RT-PCR). Results: The expression levels of miR182 and miR-210 were significantly higher in the Ad-MPE than in the BPE samples. The receiver operating characteristics curve analyses of miR-182 and miR-210 for diagnosis of AdMPE yielded areas under the receiver operating characteristic curves of 0.87 and 0.81 , respectively. Conclusion: These miRNA signatures may have a diagnostic potential for differentiating Ad-MPE from BPE.
\end{abstract}

Lung cancer is the most common cause of cancer-related deaths worldwide (1). Malignant pleural effusion (MPE) has been reported to be the initial presentation of cancer in $10-50 \%$ of patients, and half of all patients with lung cancer develop MPE at some time during their disease (2). Although MPE can occur in patients with all histological types of lung cancer, they are more common in patients with adenocarcinoma (3). MPEs are usually diagnosed by pathological analysis, however, the sensitivity of cytology is $50-70 \%$ even when thoracenteses are repeated, and repeated aspiration is only helpful in an additional $10 \%$ of cases (4). Therefore, establishment of a novel diagnostic marker of MPE is desired.

Correspondence to: Akihisa Mitani, MD, Ph.D., The Department of Respiratory Medicine, The University of Tokyo Hospital, 7-3-1 Hongo, Bunkyo-ku, Tokyo, 113-8655, Japan. Tel: +81 338155411, Fax: +81 338140021, e-mail: mitania-int@h.u-tokyo.ac.jp

Key Words: Exosome, lung adenocarcinoma, microRNA, pleural effusion, diagnosis.
Exosomes are small membrane vesicles of endocytic origin and were initially demonstrated in the peripheral circulation of patients with cancer (5). Tumor-released exosomes in peripheral blood contain microRNAs (miRNAs) (6). Exosomal miRNA reflects the miRNA signature of the parental tumor because the profiles of circulating exosomal miRNAs are similar to those of tumor-derived miRNAs and there appears to be a significant difference in exosomal miRNA levels between patients with cancer and controls (7). Therefore, circulating extracellular miRNAs have been recognized to be minimally-invasive biomarkers for cancer diagnosis $(8,9)$. There are some reports that describe cell-free DNA or cell-free miRNA expression in MPE associated with lung adenocarcinoma (Ad-MPE) (10-12). However, cell-free DNA and miRNAs occur in short fragments and originate from dying cells, which can further complicate molecular analysis (13). It is unclear to what extent these cells represent the genotype of the prevailing population of malignant cells (14). Exosomal miRNAs may be better diagnostic biomarkers because of their stability in body fluids, which may be explained by the fact that exosomes protect miRNAs from degradation (15). Therefore, analyzing exosomal miRNAs would provide less contaminated and more cancer-specific results than analyzing cell-free DNAs and miRNAs.

Emerging evidence suggests that several miRNAs function as biomarkers for diagnosis of lung cancer. Among those miRNAs, $m i R-21$, $m i R-31$, $m i R-182$, and $m i R-210$ have been reported to be up-regulated in lung adenocarcinoma tissue and peripheral blood (16-18). However, little is known about the diagnostic significance of these miRNAs as exosome content in PE. The aim of the present study was to determine whether these miRNAs in exosome might be diagnostic biomarkers for differentiating Ad-MPE and benign PE (BPE).

\section{Materials and Methods}

Patients and sample collection. Pleural effusion samples $(n=56$ : Ad-MPE, $n=41$; BPE, $n=15$ ) from patients with lung adenocarcinoma and other diseases were collected between the July 2014 and June 2018 at the University of Tokyo Hospital. 
Matched serum samples were obtained from patients with lung adenocarcinoma $(n=20)$. The time interval between collection of $\mathrm{PE}$ and serum samples was $0-48$ days (median=1 day). These patients did not receive any systemic treatment such as chemotherapy or surgery between PE and serum sampling (three patients received local radiotherapy during this period). The samples were centrifuged at $900 \times g$ for $10 \mathrm{~min}$ and the supernatants were obtained and stored at $-80^{\circ} \mathrm{C}$ for further analysis. The PE was categorized as MPE if the cytology or cell block specimen was positive for malignancy. Patients with negative cytology were also diagnosed as having MPE if they had disseminated malignancy without alternative causes for the effusion. This study was approved by the Institutional Review Board (approval number 10226-3), and written informed consent was obtained from all participants.

Extraction of exosomal miRNA. Total exosome containing miRNA was extracted from samples by using total exosome isolation reagent (Invitrogen, Carlsbad, CA, USA) according to the manufacturer's protocol. In brief, frozen samples were thawed at room temperature and then centrifuged at $2,000 \times g$ for $30 \mathrm{~min}$ to remove cellular debris. A total of $1000 \mu \mathrm{l}$ for PE and $250 \mu \mathrm{l}$ for serum was used for downstream analysis. Each sample was combined with $0.2 \times$ the volume of total exosome isolation reagent and then mixed well. The samples were incubated at $4^{\circ} \mathrm{C}$ for $30 \mathrm{~min}$ and then centrifuged at room temperature at $10,000 \times g$ for $10 \mathrm{~min}$. The exosome pellet was resuspended in phosphate-buffered saline and then stored at $-20^{\circ} \mathrm{C}$.

RNA recovery using total exosome RNA and protein isolation kit. A Total Exosome RNA and Protein Isolation Kit (Invitrogen) was used according to the manufacturer's instructions with slight modifications. In brief, each sample was lysed with denaturing solution, and RNA was extracted with acid-phenol:chloroform and $100 \%$ ethanol. After washing, samples were dried by spinning and $50 \mu \mathrm{l}$ of preheated elution solution was applied once. After centrifugation, the eluate containing the RNA was collected and stored at $-20^{\circ} \mathrm{C}$.

Real-time reverse transcription quantitative polymerase chain reaction analysis of RNA sequences isolated from exosomes. A reverse transcription (RT) master mix was prepared for each sample using the TaqMan MicroRNA Reverse Transcription Kit reagents (Applied Biosystems, Foster City, CA, USA) with gene-specific RT primers for each miRNA target according to the manufacturer's instruction with slight modifications. A total of $7 \mu$ of each sample and $3 \mu \mathrm{l}$ of RT primer was added to $5 \mu \mathrm{l}$ of master mix. Each tube was placed into a PC-818S thermal cycler (ASTEC, Kasuya, Fukuoka, Japan) and incubated as follows: $16^{\circ} \mathrm{C}$ for $30 \mathrm{~min}, 42^{\circ} \mathrm{C}$ for $30 \mathrm{~min}$, and $85^{\circ} \mathrm{C}$ for $5 \mathrm{~min}$.

RT-quantitative polymerase chain reaction was performed using an Mx3000P QPCR instrument (Agilent Technologies, Santa Clara, CA, USA) along with TaqMan Universal PCR Master Mix II, each TaqMan small RNA assay (Applied Biosystems), and each RT reaction with the following thermocycler protocol: $50^{\circ} \mathrm{C}$ for 2 $\min , 95^{\circ} \mathrm{C}$ for $10 \mathrm{~min}$, and $\left(95^{\circ} \mathrm{C}\right.$ for $15 \mathrm{~s}$ and $60^{\circ} \mathrm{C}$ for $\left.60 \mathrm{~s}\right)$ for 40 cycles. All reactions were performed in triplicate. The comparative cycle threshold method was used to determine the relative expression levels of the target miRNAs with reference gene $(m i R-16)$.
Table I. Patient characteristics.

\begin{tabular}{|c|c|c|c|}
\hline \multirow[t]{2}{*}{ Characteristic } & \multicolumn{2}{|c|}{ Value } & \multirow[b]{2}{*}{$p$-Value } \\
\hline & $\begin{array}{l}\text { Ad-MPE } \\
(\mathrm{n}=41)\end{array}$ & $\begin{array}{c}\text { BPE } \\
(\mathrm{n}=15)\end{array}$ & \\
\hline \multicolumn{4}{|l|}{ Age, years } \\
\hline Median (range) & $68(49-87)$ & $73(37-95)$ & 0.51 \\
\hline \multicolumn{4}{|l|}{ Gender, $\mathrm{n}$} \\
\hline Male & 28 & 8 & 0.35 \\
\hline Female & 13 & 7 & \\
\hline \multicolumn{4}{|l|}{ Smoking status, $\mathrm{n}$} \\
\hline Current/former & 26 & 12 & 0.34 \\
\hline Never & 15 & 3 & \\
\hline Amyloidosis, $\mathrm{n}$ & & 1 & \\
\hline Parapneumonic effusion, $\mathrm{n}$ & & 1 & \\
\hline Chylothorax, $\mathrm{n}$ & & 1 & \\
\hline Congestive heart failure, $\mathrm{n}$ & & 1 & \\
\hline Benign asbestos-related effusion, $n$ & & 1 & \\
\hline Hypoalbuminemia, $\mathrm{n}$ & & 2 & \\
\hline Empyema, $\mathrm{n}$ & & 2 & \\
\hline \multicolumn{4}{|l|}{ Reactive effusion, $\mathrm{n}$} \\
\hline Post operative & & 1 & \\
\hline Inflammation, $\mathrm{n}$ & & 4 & \\
\hline Pneumothorax, $\mathrm{n}$ & & 1 & \\
\hline \multicolumn{4}{|l|}{ Metastatic site, $\mathrm{n}$} \\
\hline Brain & 12 & NA & \\
\hline Bone & 9 & & \\
\hline Liver & 3 & & \\
\hline Lymph node & 4 & & \\
\hline \multicolumn{4}{|l|}{$\mathrm{CEA}, \mathrm{ng} / \mathrm{ml}$} \\
\hline Median & 46.9 & 1.6 & $<0.0001$ \\
\hline
\end{tabular}

Ad-MPE, Malignant pleural effusion associated with lung adenocarcinoma; BPE, benign pleural effusion; CEA, carcinoembryonic antigen; NA, not applicable.

Immunoassay for carcinoembryonic antigen. Levels of carcinoembryonic antigen (CEA), which is the most commonly used biomarker for lung adenocarcinoma, were measured using a chemiluminescent enzyme immunoassay (SRL, Shinjuku-ku, Tokyo, Japan) for PE and an immune enzymatic assay (Tosoh, Minato-ku, Tokyo, Japan) for serum.

Statistical analysis. Differences in age between the two groups were evaluated by performing a $t$-test. Fisher's exact tests were performed to assess the distribution of sex and smoking status between groups. The Mann-Whitney $U$-test was used to determine statistically significant differences in miRNA expression between independent groups. Spearman's rho coefficient was used to assess correlations between miRNA expression level in PE and serum, and CEA and miRNA expression level in PE. Differences with $p$-values less than 0.05 were considered statistically significant. All statistical analyses were performed using GraphPad Prism, version 5.04 (GraphPad Software, San Diego, CA, USA) and EZR, version 1.36 (Saitama Medical Center, Saitama-shi, Saitama, Japan, and Jichi Medical University, Shimotsukeshi, Tochigi, Japan) (19), which is a graphical user interface for $\mathrm{R}$ (The $\mathrm{R}$ Foundation for Statistical Computing, version 2.13.0). 
A

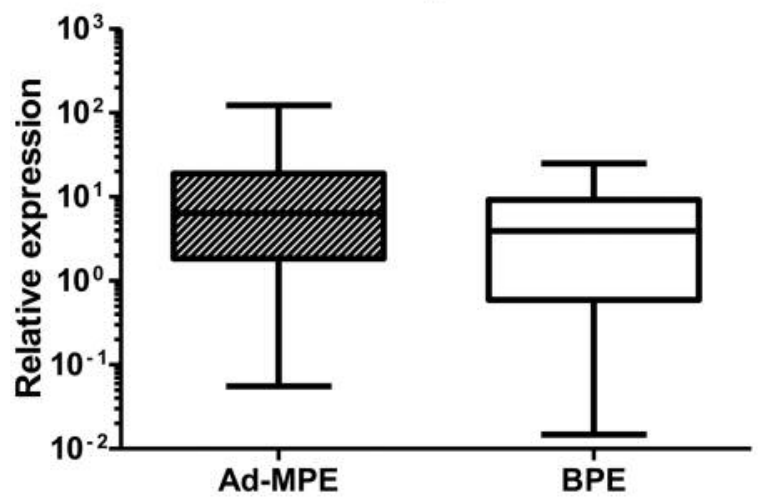

C

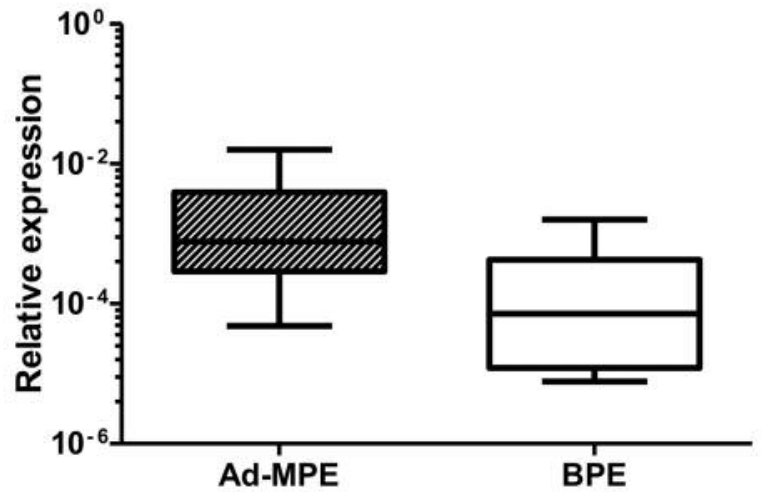

B

miR-31

$p=0.60$

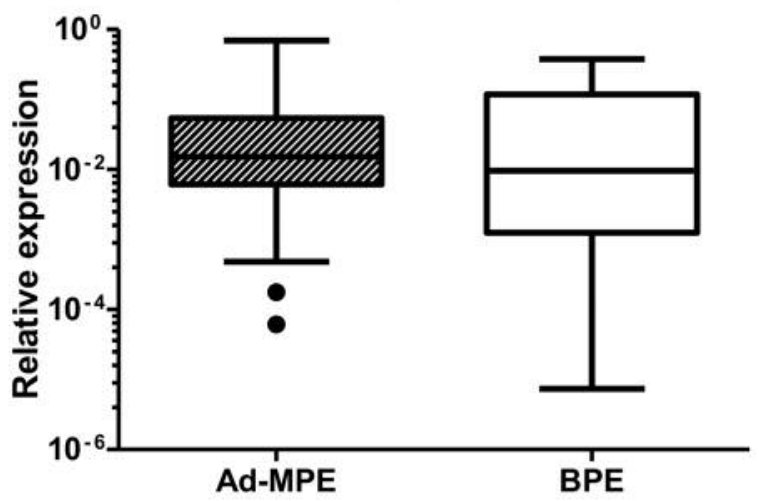

D

miR-210

$p<0.001$

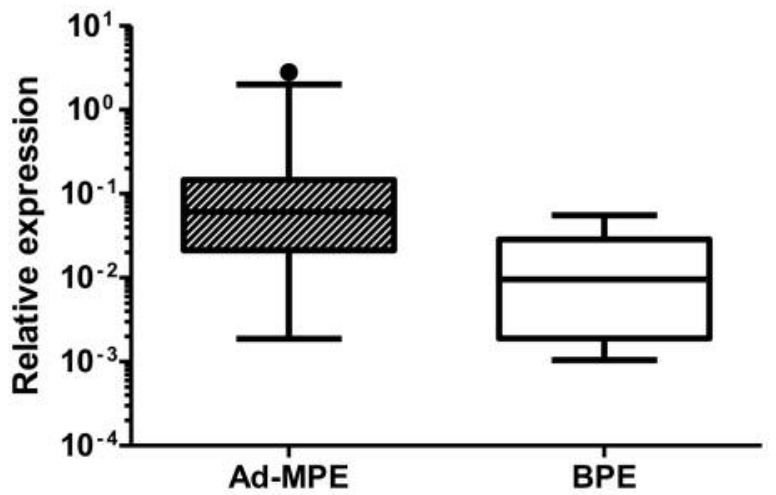

Figure 1. Expression levels of miR-21 (A), miR-31 (B), miR-182 (C), and miR-210 (D) in malignant pleural effusion associated with lung adenocarcinoma (Ad-MPE) and benign pleural effusion (BPE). The expression levels of miR-182 and miR-210 in the Ad-MPE samples were significantly higher than those in the BPE samples. The horizontal bars indicate the median value. miR-16 was used as a reference gene.

\section{Results}

Patient characteristics. There were no significant differences in the characteristics of the patients with regard to age, sex, and smoking status between the groups (Table I). Among 41 Ad-MPE samples, 39 were cytology-positive.

Expression levels of miRNAs and CEA in PE and serum. The expression levels of $m i R-182$ and $m i R-210$ were significantly higher in the Ad-MPE samples than in the BPE samples (Figure 1). In contrast, the expression levels of $m i R-21$ and $m i R-31$ were comparable between the two groups. The median CEA level was significantly higher in the Ad-MPE samples than in the BPE samples $(46.9 \mathrm{ng} / \mathrm{ml} v s .1 .6 \mathrm{ng} / \mathrm{ml}, p<0.0001)$. CEA was not significantly correlated with the expression levels of miRNAs in PE (Figure 2). There were no significant differences in miRNA expression levels in PE between patients with extrathoracic metastases of lung adenocarcinoma $(\mathrm{n}=22)$ and those without $(\mathrm{n}=19)(m i R-21, p=0.49 ; m i R-31$, $p=0.89 ; m i R-182, p=0.87 ; m i R-210, p=0.21)$. Twenty patients with lung adenocarcinoma underwent serum miRNA testing (matched serum). Among them, no significant correlation was found between PE and serum miRNA expression levels (Figure 3), which seemed to imply that miRNA expression in PE was independent of that in serum.

Diagnostic performance of miRNA for Ad-MPE. The performance of each miRNA for diagnosing Ad-MPE and BPE was evaluated by receiver operating characteristics (ROC) curve analysis. The cut-off value was selected at the point of the 

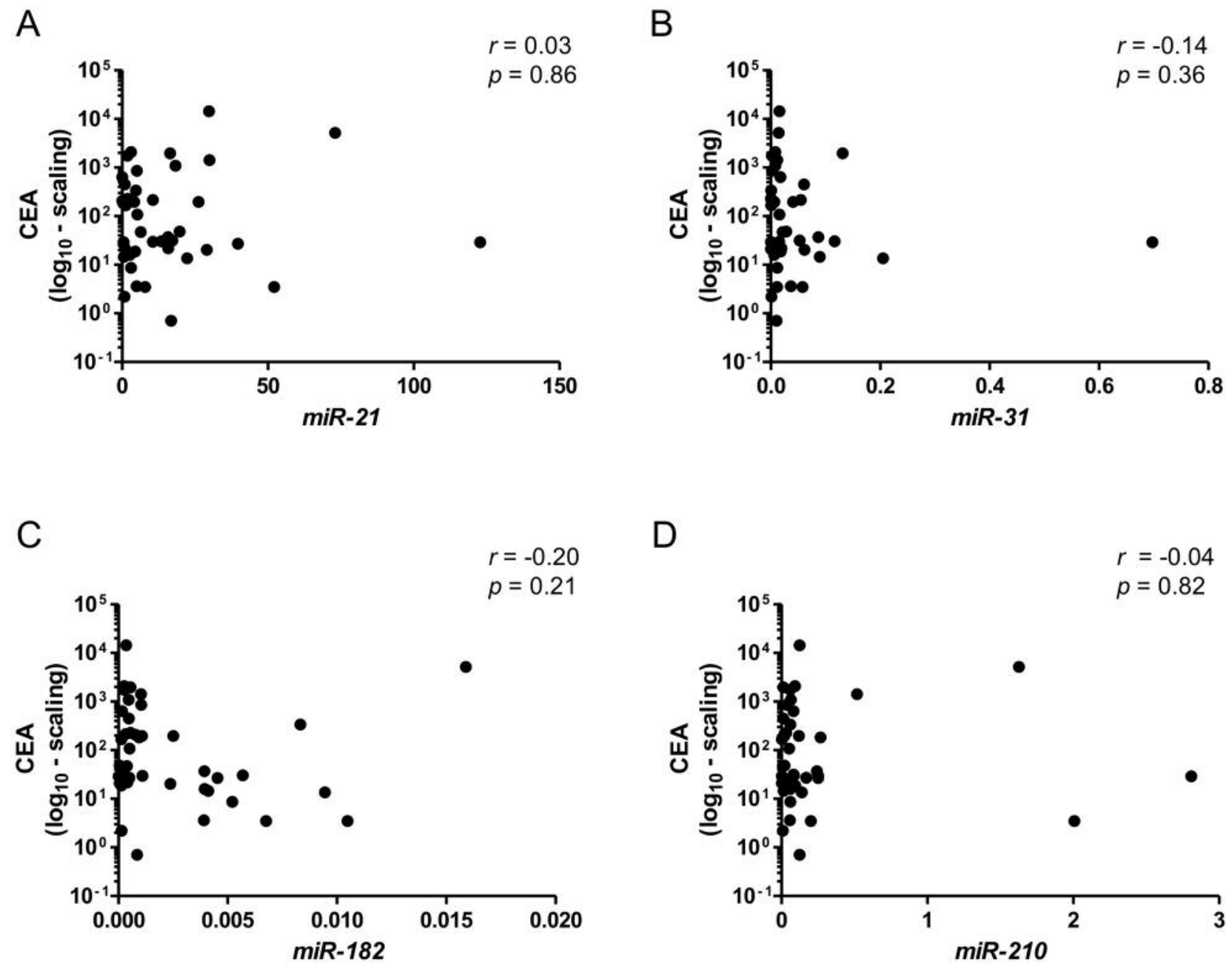

Figure 2. Correlation between carcinoembryonic antigen (CEA) and miR-21 (A), miR-31 (B), miR-182 (C), and miR-210 (D) in pleural effusion in patients with lung adenocarcinoma. The expression levels of microRNAs and CEA were not significantly correlated. CEA levels were log-transformed.

highest Youden index. The area under the curve (AUC) values for $m i R-182$ and $m i R-210$ for differentiating Ad-MPE from BPE were 0.87 (sensitivity $=92.7 \%$; specificity $=73.3 \%$ ) and 0.81 ( sensitivity $=58.5 \%$; specificity=93.3\%), respectively (Figure 4). Combining assessment of these two miRNAs (miR-182 and $m i R-210)$ increased the diagnostic performance, yielding an AUC of 0.88 (95\% confidence interval=0.78-0.97).

\section{Discussion}

Our study demonstrated that Ad-MPE samples had higher expression levels of exosomal miR-182 and miR-210 than those of the BPE samples. The ROC curve analyses revealed that $m i R-182$ and $m i R-210$ for diagnosis of Ad-MPE yielded AUCs of 0.87 and 0.81 , respectively. The AUC for these miRNAs combined was 0.88 . These findings indicate that these miRNAs are potential diagnostic markers of MPE in patients with lung adenocarcinoma.

CEA is a commonly used serum biomarker for patients with lung adenocarcinoma, and its diagnostic usefulness is also reported in Ad-MPE (12, 20-23). However, compared with serum CEA, CEA in PE shows a variable cutoff value, and its sensitivity has been found to be poor in meta-analysis (24). Indeed, five Ad-MPE samples had CEA levels below cutoff (5.0 $\mathrm{ng} / \mathrm{ml}$ ) in our study. On the other hand, three of these samples had higher expression levels of both $m i R-182$ and $m i R-210$, and one sample had higher expression level of $m i R-182$ than the cutoff value. The expression of these miRNAs in PE was not correlated to the CEA level; therefore, the miRNA signature in PE might have complementary value for diagnosing Ad-MPE.

$m i R-182$ is a member of the $m i R-183$ family, and the $m i R$ 182-96-183 cluster is located in the same chromosomal region 

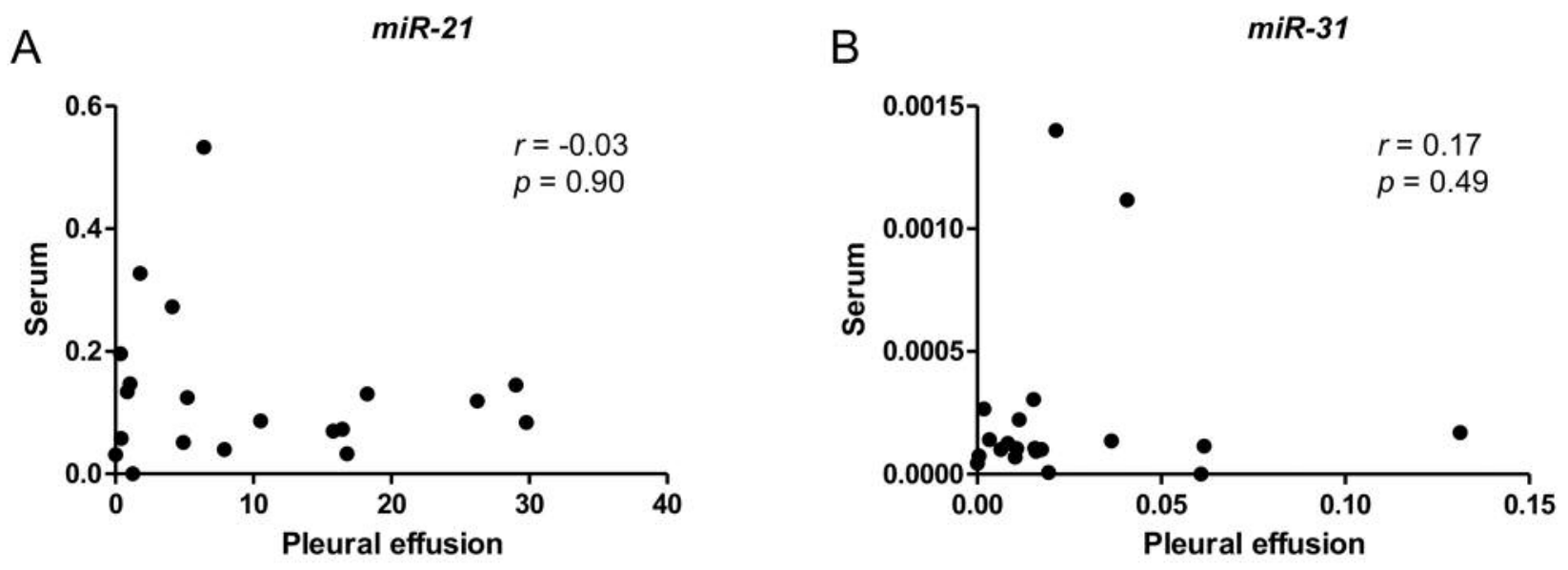

C

miR-182

$\mathrm{D}$
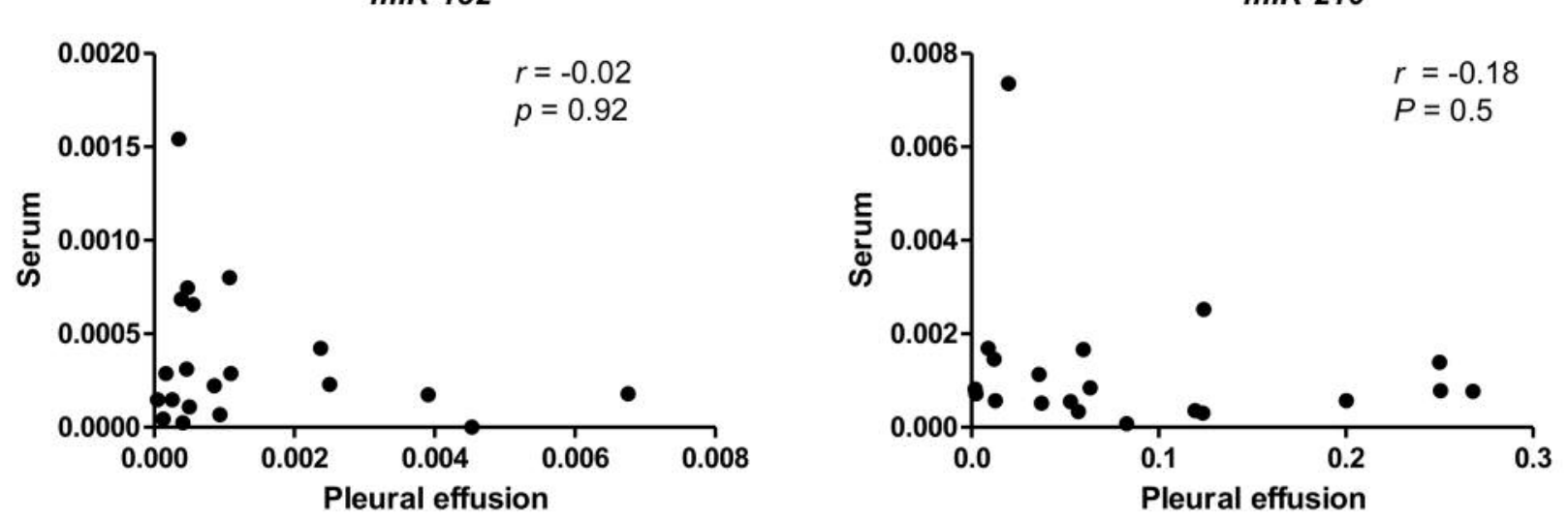

Figure 3. Correlation between microRNA expression in serum and in pleural effusion in patients with lung adenocarcinoma: miR-21 (A), miR-31 $(B)$, miR-182 (C), and miR-210 (D). No significant correlation was found between pleural effusion and serum microRNA expression levels.

(7q32.2). The molecule functions as an oncogene via promotion of tumor cell growth and migration by targeting the transcription factor early growth response protein 1 , by stimulating angiogenesis via fibroblast growth factor receptor substrate 2 (25). In addition, Barshack et al. reported that $m i R$ 182 was overexpressed in primary lung cancer tissue and concluded that its expression level was useful for distinguishing lung primary tumors from metastases to the lung (26). We investigated the miR-182 expression levels of MPE samples in seven patients with other metastatic disease (ovarian cancer, $\mathrm{n}=2$; malignant melanoma, $\mathrm{n}=1$; urothelial cancer, $\mathrm{n}=1$; hypopharyn $\mathrm{x}$ cancer, $\mathrm{n}=1$; malignant lymphoma, $\mathrm{n}=1$; thyroid cancer; $\mathrm{n}=1$ ), but there were no significant differences in the expression level between Ad-MPE and metastatic MPE (data not shown). To evaluate the diagnostic significance of $m i R-182$ in PE, further studies are warranted with a larger number of samples. $m i R-210$ is recognized as an important regulator of the cellular response to hypoxia (27). Intrapleural cavities in healthy individuals exhibit negative pressures (28), and physiologicalnegative pressure is associated with an oxygen content of less than $4 \%$ (29). Furthermore, in malignant disease, hypoxia evolves because of the consumption of oxygen by proliferating cancer cells (30). These conditions might lead to a high expression level of $m i R-210$ in MPE. Overexpression of $m i R$ 210 in human umbilical vein endothelial cells enhances vascular endothelial growth factor (VEGF) expression and promotes angiogenesis in vitro (31). VEGF is recognized as an important cytokine in the formation of MPE (32). High levels of VEGF produced by tumor cells, mesothelial cells, and infiltrating immune cells increased vascular permeability, cancer cell transmigration and angiogenesis (33). Therefore, increased expression of $m i R-210$ itself would contribute to production of MPE by modulating that of VEGF. 


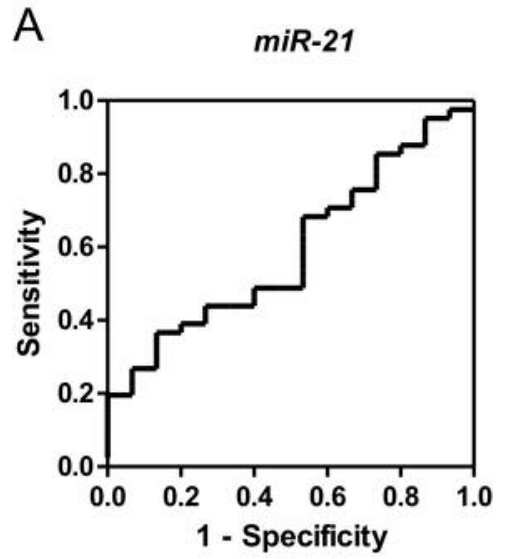

C

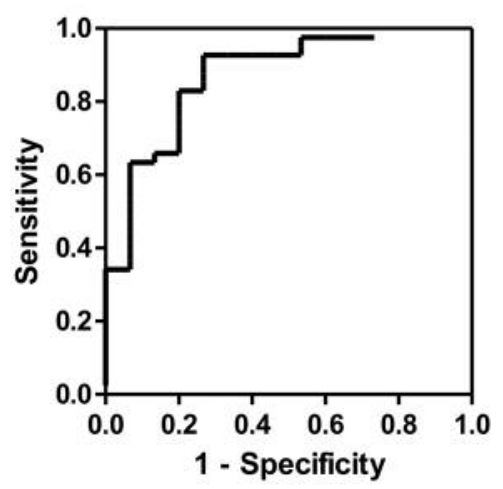

B miR-31

\author{
$\mathrm{AUC}=0.59$ \\ $(95 \% \mathrm{Cl}=0.43-0.75)$ \\ $p=0.29$ \\ Cut-off 15.53 \\ Sensitivity $36.6 \%$ \\ Specificity $92.9 \%$
}

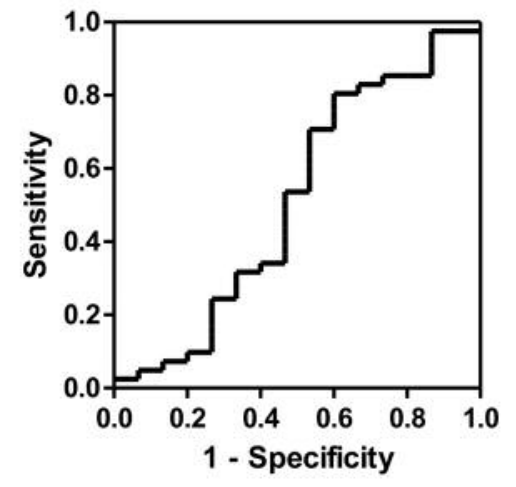

AUC $=0.51$

$(95 \% \mathrm{Cl}=0.32-0.70)$

$p=0.89$

Cut-off 0.024

Sensitivity $80.5 \%$

Specificity $40.0 \%$
AUC $=0.87$
$(95 \%$ Cl $=0.76-0.98)$
$p<0.001$

\section{Cut-off 0.0001}

Sensitivity $92.7 \%$

Specificity $73.3 \%$
$\mathrm{D}$

$\operatorname{miR}-210$

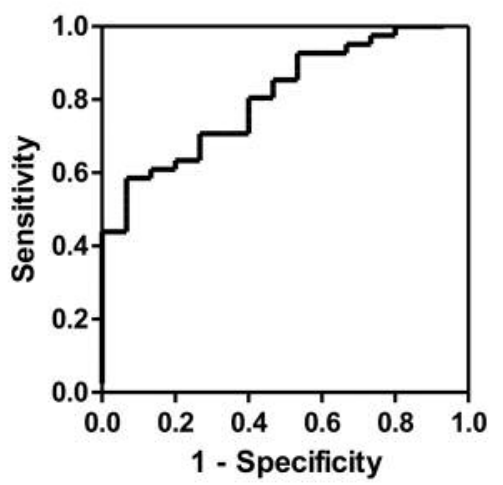

$\mathrm{AUC}=0.81$

$(95 \% \mathrm{Cl}=0.69-0.93)$

$p<0.001$

Cut-off 0.056

Sensitivity $58.5 \%$

Specificity $93.3 \%$

Figure 4. Receiver operating characteristics curves showing the diagnostic performance of expression of miR-21 (A), miR-31 (B), miR-182 (C), and miR-210 (D) for differentiating malignant pleural effusion associated with lung adenocarcinoma from benign pleural effusion. The area under the curves of miR-182 and miR-210 were significantly diagnostic.

$m i R-21$ inhibits expression of phosphatase and tensin homolog and stimulates growth and invasion of non-small cell lung cancer cells (34). miR-31 increases cell migration, invasion, and proliferation in an extracellular signalregulated kinase 1/2 signaling-dependent manner (35). These miRNAs have been shown to be deregulated in lung cancer in many studies; however, the expression levels of these miRNAs were not significantly different among two groups. The cause for this discrepancy requires further investigation. Our results demonstrated that miRNA expressions in serum and PE were not correlated, and the miRNA profiles were not different between patients with extrathoracic metastases and those without. Although the study sample size was small, these results indicate that miRNAs in PE might be expressed separately from that in circulating blood.

Our study had several limitations. Firstly, small sample sizes were used. Secondly, some of the patients included in this study were not cancer therapy-naïve; therefore, we cannot exclude the possibility that previous treatments may have influenced miRNA expressions in PE and serum. Thirdly, there were no serum samples from patients with BPE, thus miRNA expression levels in PE and serum in patients with benign disease need to be validated.

In conclusion, we demonstrated exosomal miRNA profiles in the Ad-MPE and the BPE samples and showed that $m i R$ 182 and $m i R-210$ expression could be used as novel diagnostic tools for discriminating Ad-MPE from BPE. We propose that these miRNAs may be useful and minimallyinvasive screening biomarkers for diagnostic evaluation of PEs. These results need to be clarified in a larger cohort of patients.

\section{Acknowledgements}

The Authors would like to acknowledge the staff from the University of Tokyo Hospital for their contribution to data collection. 


\section{Conflicts of Interest}

The Authors declare that they have no conflict of interest in regard to this study.

\section{References}

1 Torre LA, Bray F, Siegel RL, Ferlay J, Lortet-Tieulent J and Jemal A: Global cancer statistics, 2012. CA Cancer J Clin 65(2): 87-108, 2015.

2 Neragi-Miandoab S: Malignant pleural effusion, current and evolving approaches for its diagnosis and management. Lung Cancer 54(1): 1-9, 2006.

3 Johnston WW: The malignant pleural effusion. A review of cytopathologic diagnoses of 584 specimens from 472 consecutive patients. Cancer 56(4): 905-909, 1985.

4 Hooper C, Lee YC, Maskell N and Group BTSPG: Investigation of a unilateral pleural effusion in adults: British thoracic society pleural disease guideline 2010. Thorax 65(Suppl 2): ii4-17, 2010.

5 Taylor DD and Doellgast GJ: Quantitation of peroxidaseantibody binding to membrane fragments using column chromatography. Anal Biochem 98(1): 53-59, 1979.

6 Tickner JA, Urquhart AJ, Stephenson SA, Richard DJ and O'Byrne KJ: Functions and therapeutic roles of exosomes in cancer. Front Oncol 4: 127, 2014

7 Mitchell PS, Parkin RK, Kroh EM, Fritz BR, Wyman SK, Pogosova-Agadjanyan EL, Peterson A, Noteboom J, O'Briant $\mathrm{KC}$, Allen A, Lin DW, Urban N, Drescher CW, Knudsen BS, Stirewalt DL, Gentleman R, Vessella RL, Nelson PS, Martin DB and Tewari M: Circulating micrornas as stable blood-based markers for cancer detection. Proc Natl Acad Sci USA 105(30): 10513-10518, 2008.

8 Schwarzenbach H, Nishida N, Calin GA and Pantel K: Clinical relevance of circulating cell-free micrornas in cancer. Nat Rev Clin Oncol 11(3): 145-156, 2014.

9 Wang H, Wu S, Zhao L, Zhao J, Liu J and Wang Z: Clinical use of micrornas as potential non-invasive biomarkers for detecting non-small cell lung cancer: A meta-analysis. Respirology 20(1): 56-65, 2015.

10 Wang T, Lv M, Shen S, Zhou S, Wang P, Chen Y, Liu B, Yu L and Hou Y: Cell-free microrna expression profiles in malignant effusion associated with patient survival in non-small cell lung cancer. PLoS One 7(8): e43268, 2012.

11 Sriram KB, Relan V, Clarke BE, Duhig EE, Windsor MN, Matar KS, Naidoo R, Passmore L, McCaul E, Courtney D, Yang IA, Bowman RV and Fong KM: Pleural fluid cell-free DNA integrity index to identify cytologically negative malignant pleural effusions including mesotheliomas. BMC Cancer 12: 428, 2012.

12 Han HS, Yun J, Lim SN, Han JH, Lee KH, Kim ST, Kang MH, Son SM, Lee YM, Choi SY, Yun SJ, Kim WJ and Lee OJ: Downregulation of cell-free mir-198 as a diagnostic biomarker for lung adenocarcinoma-associated malignant pleural effusion. Int J Cancer 133(3): 645-652, 2013.

13 Polivka J Jr., Pesta M and Janku F: Testing for oncogenic molecular aberrations in cell-free DNA-based liquid biopsies in the clinic: Are we there yet? Expert Rev Mol Diagn 15(12): 1631-1644, 2015.

14 Caino MC and Altieri DC: Molecular pathways: Mitochondrial reprogramming in tumor progression and therapy. Clin Cancer Res 22(3): 540-545, 2016.
15 Cortez MA, Bueso-Ramos C, Ferdin J, Lopez-Berestein G, Sood AK and Calin GA: Micrornas in body fluids-the mix of hormones and biomarkers. Nat Rev Clin Oncol 8(8): 467-477, 2011.

16 Guan P, Yin Z, Li X, Wu W and Zhou B: Meta-analysis of human lung cancer microrna expression profiling studies comparing cancer tissues with normal tissues. J Exp Clin Cancer Res 31: 54, 2012.

17 Vosa U, Vooder T, Kolde R, Vilo J, Metspalu A and Annilo T: Meta-analysis of microrna expression in lung cancer. Int $\mathbf{J}$ Cancer 132(12): 2884-2893, 2013.

18 Ulivi P and Zoli W: Mirnas as non-invasive biomarkers for lung cancer diagnosis. Molecules 19(6): 8220-8237, 2014.

19 Kanda Y: Investigation of the freely available easy-to-use software 'ezr' for medical statistics. Bone Marrow Transplant 48(3): 452-458, 2013.

20 Shijubo N, Honda Y, Fujishima T, Takahashi H, Kodama T, Kuroki Y, Akino T and Abe S: Lung surfactant protein-A and carcinoembryonic antigen in pleural effusions due to lung adenocarcinoma and malignant mesothelioma. Eur Respir J 8(3): 403-406, 1995.

21 Huang WW, Tsao SM, Lai CL, Su CC and Tseng CE: Diagnostic value of HER-2/NEU, CYFRA 21-1, and carcinoembryonic antigen levels in malignant pleural effusions of lung adenocarcinoma. Pathology 42(3): 224-228, 2010.

22 Hsieh TC, Huang WW, Lai CL, Tsao SM and Su CC: Diagnostic value of tumor markers in lung adenocarcinoma-associated cytologically negative pleural effusions. Cancer Cytopathol 121(9): 483-488, 2013.

23 Gaspar MJ, De Miguel J, Garcia Diaz JD and Diez M: Clinical utility of a combination of tumour markers in the diagnosis of malignant pleural effusions. Anticancer Res 28(5B): 2947-2952, 2008.

24 Gu P, Huang G, Chen Y, Zhu C, Yuan J and Sheng S: Diagnostic utility of pleural fluid carcinoembryonic antigen and CYFRA 211 in patients with pleural effusion: A systematic review and meta-analysis. J Clin Lab Anal 21(6): 398-405, 2007.

25 Sarver AL, Li L and Subramanian S: MicroRNA mir-183 functions as an oncogene by targeting the transcription factor EGR1 and promoting tumor cell migration. Cancer Res 70(23): 9570-9580, 2010.

26 Barshack I, Lithwick-Yanai G, Afek A, Rosenblatt K, TabibianKeissar H, Zepeniuk M, Cohen L, Dan H, Zion O, Strenov Y, Polak-Charcon S and Perelman M: Microrna expression differentiates between primary lung tumors and metastases to the lung. Pathol Res Pract 206(8): 578-584, 2010.

27 Noman MZ, Janji B, Berchem G and Chouaib S: mir-210 and hypoxic microvesicles: Two critical components of hypoxia involved in the regulation of killer cells function. Cancer Lett 380(1): 257-262, 2016.

28 Matsuzaki S, Jardon K, Maleysson E, D’Arpiany F, Canis M, Bazin JE and Mage G: Carbon dioxide pneumoperitoneum, intraperitoneal pressure, and peritoneal tissue hypoxia: A mouse study with controlled respiratory support. Surg Endosc 24(11): 2871-2880, 2010.

29 Francis RJ, Segard T, Morandeau L, Lee YC, Millward MJ, Segal A and Nowak AK: Characterization of hypoxia in malignant pleural mesothelioma with fmiso pet-ct. Lung Cancer 90(1): 55-60, 2015.

30 Nabavi N, Bennewith KL, Churg A, Wang Y, Collins CC and Mutti L: Switching off malignant mesothelioma: Exploiting the hypoxic microenvironment. Genes Cancer 7(11-12): 340-354, 2016. 
31 Liu F, Lou YL, Wu J, Ruan QF, Xie A, Guo F, Cui SP, Deng ZF and Wang Y: Upregulation of microRNA-210 regulates renal angiogenesis mediated by activation of vegf signaling pathway under ischemia/perfusion injury in vivo and in vitro. Kidney Blood Press Res 35(3): 182-191, 2012.

32 Bradshaw M, Mansfield A and Peikert T: The role of vascular endothelial growth factor in the pathogenesis, diagnosis and treatment of malignant pleural effusion. Curr Oncol Rep 15(3): 207-216, 2013.

33 Duysinx BC, Corhay JL, Hubin L, Nguyen D, Henket M and Louis R: Diagnostic value of interleukin-6, transforming growth factor-beta 1 and vascular endothelial growth factor in malignant pleural effusions. Respir Med 102(12): 1708-1714, 2008.

34 Liu ZL, Wang H, Liu J and Wang ZX: Microrna-21 (mir-21) expression promotes growth, metastasis, and chemo-or radioresistance in non-small cell lung cancer cells by targeting pten. Mol Cell Biochem 372(1-2): 35-45, 2013.
35 Meng W, Ye Z, Cui R, Perry J, Dedousi-Huebner V, Huebner A, Wang Y, Li B, Volinia S, Nakanishi H, Kim T, Suh SS, Ayers LW, Ross P, Croce CM, Chakravarti A, Jin VX and Lautenschlaeger T: MicroRNA-31 predicts the presence of lymph node metastases and survival in patients with lung adenocarcinoma. Clin Cancer Res 19(19): 5423-5433, 2013.

Received October 29, 2018

Revised November 11, 2018

Accepted November 13, 2018 